\title{
TRANSFERABILITY OF MIGRATION LICENSES AND THE DISTRIBUTION OF POTENTIAL RENTS
}

\author{
Laura L. Bivins \\ Kala Krishna \\ Working Paper 8619 \\ http://www.nber.org/papers/w8619 \\ NATIONAL BUREAU OF ECONOMIC RESEARCH \\ 1050 Massachusetts Avenue \\ Cambridge, MA 02138 \\ December 2001
}

The views expressed herein are those of the authors and not necessarily those of the National Bureau of Economic Research.

(C) 2001 by Laura L. Bivins and Kala Krishna. All rights reserved. Short sections of text, not to exceed two paragraphs, may be quoted without explicit permission provided that full credit, including (C notice, is given to the source. 
Transferability of Migration Licenses and the Distribution of Potential Rents

Laura L. Bivins and Kala Krishna

NBER Working Paper No. 8619

December 2001

JEL No. F22, F13, F16

\begin{abstract}
This paper compares the effects of migration restrictions using licenses which are freely traded in a competitive labor market to those that occur when licenses are allocated to firms who are not permitted to trade them. There is reason to expect that a policy of making licenses non-transferable will not only affect production efficiency, but also to allow producers to capture more of the potential migration rents. Applications to migration policies in the Gulf Cooperation Council (GCC) countries are discussed.
\end{abstract}

Laura L. Bivins

The Pennsylvania State University
Kala Krishna

Department of Economics

523 Kern Graduate Building The Pennsylvania State University University Park, PA 16802 and NBER

kmk4@psu.edu 


\section{Introduction}

While there is a large body of work on the effects of international labor mobility, and on the brain drain, see for example Bhagwati (1976) and Hamada (1975), there has been relatively little written on how implementation and differences in implementation affect migration patterns and rents. There are major differences between countries in the extent of migration and in the way that migration policies are implemented. Countries in the Gulf Cooperation Council $(G C C)$, consisting of Bahrain, Kuwait, Oman, Qatar, Saudi Arabia, and the United Arab Emirates, have fairly high proportions of migrant workers. They comprise approximately 55 percent of the labor force in Bahrain, 65-70 percent of the labor force in Oman and Saudi Arabia, and 85-90 percent in Kuwait, Qatar, and in the United Arab Emirates. One of the most commonly adopted migration policies is the allocation of migrant work permits to domestic firms, where migrant labor must be sponsored by a firm in the host country. These permits are only good for a short time period, anywhere from six months up to two years and the sponsorship is usually nontransferable. This means that once a migrant worker has entered the country to work for a firm they must leave the country and reapply to be able to work for a different firm. On the other hand, in many western countries, the prerequisites for temporary or permanent migration are capital investment of a suitable sum in the host country, having close relatives who are citizens, or having needed skills. In most cases, the permit is with the migrant, not the employer, and it is often permanent, not temporary.

In this paper we compare the effects of transferable permits to ones which are allocated to firms who cannot trade them. The latter is similar to the way labor markets work in the $G C C$ countries. For this reason we provide some background on these countries next.

\subsection{Some Features of Labor Markets in $G C C$ Countries}

In the aftermath of the oil price increases of 1973 and 1974 severe labor shortages quickly developed in most of the $G C C$ countries. The labor shortages were for both skilled and unskilled labor. With increasing government expenditures, especially the implementation of large public infrastructure projects, there was an increased demand for both technical and professional skills as well as blue-collar labor. Also, the many-fold increase in personal incomes led to an immediate demand for labor in the household service sectors. The labor shortage was ameliorated by an influx of foreign labor arriving mostly from other Middle Eastern countries. 
Initially, migrant labor was either not regulated or the existing migration quotas were not strictly enforced in most of the $G C C$ countries.

In the 1980's and 1990's real wages of domestic workers stagnated and population growth rates increased to over four percent in several $G C C$ countries. This led to migrant labor policies becoming increasingly stringent in an effort to protect domestic jobs and wages. Today, despite stricter permit regulations, demand for migrant labor remains high. One of the major factors influencing this continuing demand for migrant labor is the attitude of $G C C$ nationals towards private sector jobs. The wealth of the oil boom was partially distributed to nationals in the form of guaranteed government jobs at inflated wages with generous benefit packages. These benefits often meet or even exceed the base salary. For example, paid leave and shorter working hours allow employees to conduct private business after working hours. Thus the government has become the employer of first and last resort. The extent of this can be seen in Kuwait, where over 90 percent of the national labor force is employed in the public sector. This gives nationals very high reservation wages and very little incentive to educate themselves in skills that are in demand by the private sector. Public subsidization of education for nationals, even to the point of making education free, has not curbed the shortage of skilled domestic workers. On the demand side, legislation that makes it difficult to fire a national working in the private sector makes it less attractive to hire locals. In response to growing unemployment, policies that restrict the use of migrant labor or encourage the use of domestic workers have been implemented. These are politically more popular than structural reform of the labor market. However, one only has to look at the steadily rising unemployment figures to see that these restrictive migration policies are not working. Unemployment rates are already far higher than anything officially admitted and unofficial estimates range from $20 \%$ in Oman and $25 \%$ in Saudi Arabia up to $30 \%$ in Bahrain. ${ }^{1}$

There is little work in the literature that analyzes implementation differences of migration policies. ${ }^{2}$ In this paper we deal with one such difference: namely the implication, in the short run, of allocating migration permits to firms in an exogenous manner and making them non-transferable. Krishna and Tan (1999) take a different approach where they compare transferability and non-transferability of licenses with uncertainty of license prices. They consider a two period model where license purchases are chosen in the first period and the value of the license

\footnotetext{
${ }^{1}$ The Economist, Apr 12, 1997.

${ }^{2}$ The closest paper to ours is Djajic (1989) who uses the same framework to look at traditional questions such as the effects of migration on trade flows.
} 
is realized in the second period. They show that the price of a license is higher under non transferability if the quota is less restrictive than a given level and vice versa otherwise. In contrast, since there is no uncertainty in our model, and as licenses are allocated based on historical shares and political connections, we take the allocation of licenses as given and look at the effects of transferability and non-transferability on the distribution of license rents.

Domestic and foreign effective labor may be perfect substitutes or imperfect substitutes. We allow workers within each country to be of differing abilities where each ability type provides a certain amount of effective labor. These abilities are assumed to be observable by firms. In our setting this is equivalent to assuming that firms can offer a piece rate wage. If licenses are sold in a competitive market, the owner of the license obtains the license rents and the highest skilled workers from abroad enter the domestic country. The same results are obtained when licenses are initially allocated to firms and the licenses are transferable. Migrants, other than the marginal ones, are better off migrating so that potential license rents are shared.

What if licenses are allocated to firms and are not transferable? If domestic and foreign labor are homogeneous and the allocation of licenses is such that all firms employ both domestic and foreign labor in equilibrium, then all firms have the same marginal product of effective labor which is equal to the domestic wage. Firms with more licenses merely reap more rents. In this case there is no difference in the distribution of licenses rents from the transferable case and no efficiency loss. However, if the allocation of licenses is severely distorted, so that some firms employ only foreign labor, then there will be an efficiency loss if the marginal product of labor is not equalized across all firms. We show that firms with less binding, or larger allocations of licenses will offer employment to lower quality migrants. However, economy-wide the same migrant labor types enter as would have had the licenses been transferable. Thus, one might ask what is the effect of distorted non-transferable licenses on the domestic economy? In addition to the inefficiency caused by firms having different marginal products of effective labor, and hence not being on the production possibility frontier, we show that this will reduce the share of migration rents to migrant workers given certain conditions on the production function. If domestic and foreign labor are imperfectly substitutable, then the outcome is similar to that in the distorted homogeneous labor case.

We proceed as follows. In Section 2 we set up our basic model where domestic and foreign labor are perfect substitutes. We first look at transferable licenses 
so that marginal products of effective labor are equalized across firms. We then look at non-transferable licenses where the marginal products of effective labor need not be equalized across firms, and finally, at the many firm case. In Section 3 we extend our analysis to the case with imperfect labor substitutes. Section 4 contains some final thoughts.

\section{Perfect Substitutes}

There are two countries, domestic and foreign. There are a large number of identical firms in the domestic country with three factors of production, capital, domestic effective labor and foreign effective labor. There is a single good produced using the factors of production, which has a price of unity. Let domestic and foreign wages per effective unit of labor be represented by $w, w^{*}$. We assume that the foreign country is large so that its wage is fixed. The transportation costs of migration are assumed to be zero. The equilibrium domestic wage per effective labor unit, $w$, is determined in a general equilibrium framework where the equilibrium wage is a function of the total number of licenses allocated in the economy.

Workers are distributed over a continuum of ability types, $\theta \in[0,1]$. One unit of type $\theta$ labor is equivalent to $\theta$ units of effective labor. The function $g(\theta)$ represents the density function over labor types at home and abroad, while $N$ and $N^{*}$ denote the population size of the domestic and foreign countries. For simplicity, we assume that $g(\theta)$ is uniform.

In order to model the $G C C$ migrant labor market more closely, we assume that migration permits are allocated to firms in the domestic country. Each firm is initially allocated $Q_{i}$ licenses. The total migration licenses allocated in the economy is $\bar{Q}=\sum_{i} Q_{i}$. Each worker must have a migration permit to enter and work in the domestic country.

\subsection{Transferable Licenses}

The symmetric two firm model where foreign and domestic labor are perfectly substitutable is illustrated in Figure 1. The total effective labor in the domestic economy from domestic and migrant workers is measured on the horizontal axis, where $E$ is the size of the domestic labor force and $E^{*}=N^{*} \int_{\underline{\theta}}^{1} \theta g(\theta) d \theta$ is the size of the migrant labor force given that $\bar{Q}$ licenses are allocated in the economy 
Figure 1: A Competitive Labor Market: All Firms Use Domestic Labor

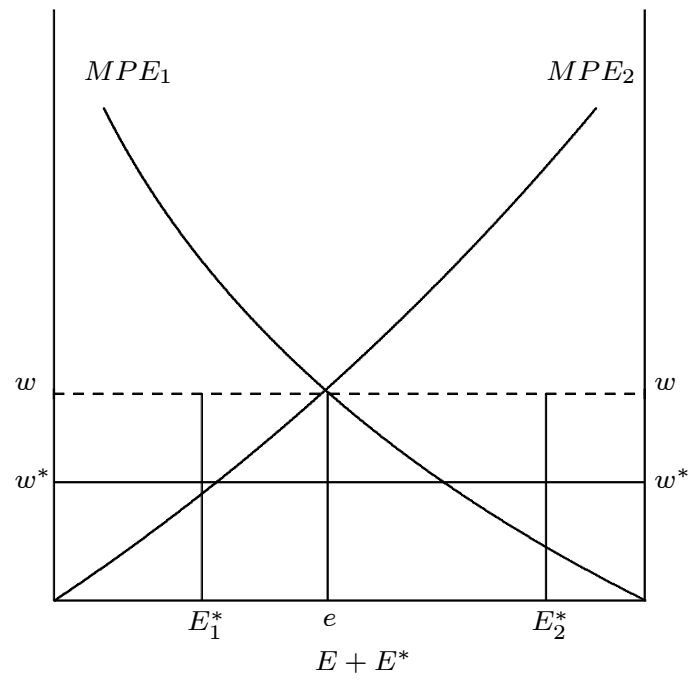

and that $\underline{\theta}$ is the marginal migrant worker that chooses to work in the domestic country. The marginal product of effective labor of each firm is measured on the vertical axis. We will show that firms will use the same amount of effective labor, $e$, if licenses are transferable.

The competitive equilibrium can be constructed assuming that firms can identify foreign labor by its type and offer a wage schedule, $W(\theta)$, over labor types. To hire a migrant worker firms also incur the cost of either buying a license at the market price or forgoing the benefit of selling the license to another firm. The cost of hiring a migrant worker thus takes the form $W(\theta)+L$, where $W(\theta)$ is the wage offered for each ability type and $L$ is the market price of a license. ${ }^{3}$ The equilibrium wage schedule offered to migrant workers must have the following properties.

1. Indifference: A firm must be equally well off whichever type of labor it ends up hiring. If this was not the case, the preferred workers would have their wages bid up. This implies that each firm must have the same cost per effective unit of labor independent of which skill type it hires.

The indifference property can be written as

$$
\frac{W\left(\theta^{\prime}\right)+L}{\theta^{\prime}}=\frac{W(\theta)+L}{\theta}=w \text { for all } \theta, \theta^{\prime} \text { that are hired by the firms. }
$$

where $w$ is the domestic wage per unit of effective labor. A firm which offers

\footnotetext{
${ }^{3}$ Since each license allows the firm to hire one worker rather than one effective labor unit, the license price does not depend on the type of the worker.
} 
Figure 2: Transferable Licenses in a Competitive Labor Market

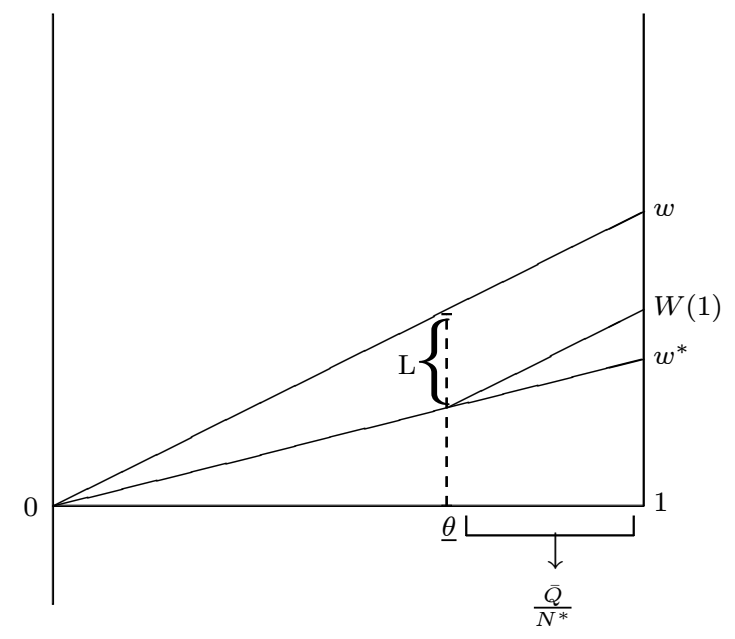

a higher (lower) wage than the going one will have excess supply (demand) so all firms must offer the same effective wage. Hence the wage schedule offered to migrant workers will be,

$$
W(\theta)=w \theta-L .
$$

In Figure 2, the domestic wage schedule is given by the line $0 w$ and the foreign wage schedule is given by the line $0 w^{*}$, where skill types are measured on the horizontal axis and wages received are measured on the vertical axis. The equilibrium wage schedule offered to migrant workers, $W(\theta)$, is just the domestic wage schedule shifted down by the value of a migration license, $L$, which is a function of the total license allocation. The marginal migrant worker, $\underline{\theta}$, is determined so that only $\bar{Q}$ workers enter. For migration to exist it must be that $w>w^{*}$. Since the difference in wages from migrating is increasing in the productivity of a worker, only the highest types will migrate. Potential rents are shared between domestic firms and migrant workers as migrants, other than the marginal ones, are better off migrating than not.

What is the equilibrium license price $L$ ? Since the marginal migrant worker, $\underline{\theta}$, will be indifferent between migrating and receiving a wage of $w \underline{\theta}-L$ or not migrating and receiving $w^{*} \underline{\theta}$, this gives us,

$$
L=\left[w-w^{*}\right] \underline{\theta} .
$$

Then $\underline{\theta}$, is determined by the constraint on the number of licenses, $\bar{Q}$, allocated 
in the economy, or by

$$
\bar{Q}=N^{*} \int_{\underline{\theta}}^{1} g(\theta) d \theta .
$$

With $\theta$ distributed uniformly,

$$
\underline{\theta}=1-\frac{\bar{Q}}{N^{*}}
$$

This gives the total foreign effective labor used, $E^{*}$, coming from workers between $\underline{\theta}$ and unity,

$$
E^{*}=N^{*} \int_{\left[1-\frac{\bar{Q}}{N^{*}}\right]}^{1} \theta g(\theta) d \theta .
$$

2. Market Clearing: Domestic wages are such that the horizontal sum of the marginal value product of effective labor across all firms equals total effective labor supply $E+E^{*}$. We assume that firms are symmetric other than their license allocations and have a fixed factor $K$ so that labor has diminishing marginal product. If license are transferable, or they are not transferable but all firms are willing to hire some domestic labor, then all firms must be indifferent between hiring domestic and foreign labor and $w$ must be the marginal value product of an effective unit of foreign labor as well. The license price can be interpreted as the shadow benefit of a license and firms with more licenses have more rents. In equilibrium all firms offer the same wage per effective unit of labor, employ the same amount of effective labor denoted by $E_{i}^{T}=\frac{E+E^{*}}{M}$, where $M$ is the number of firms, and employ the average quality of migrant labor that is hired in the domestic country.

\subsection{Non-transferable Licenses}

Why use non-transferable migration licenses in $G C C$ countries? Clearly this migration policy is inefficient from a labor allocation perspective. However, with non-transferable licenses, under certain conditions, firms offer a wage schedule in equilibrium that gives them a greater portion of the license rents from migration! Since licenses are often allocated in $G C C$ countries on the basis of political ties, distorted license allocations are common. For example, in Kuwait, once a firm is licensed to operate it must apply to the Ministry of Social Affairs and Labor for a certain allocation of workers where this allocation is based on an inspection by staff of the Ministry. Political connections play a large role in the number of licenses that each firm is allocated. In addition, the percentage of the national 
Figure 3: Marginal Product of Effective Labor as a Function of Quota Allocation

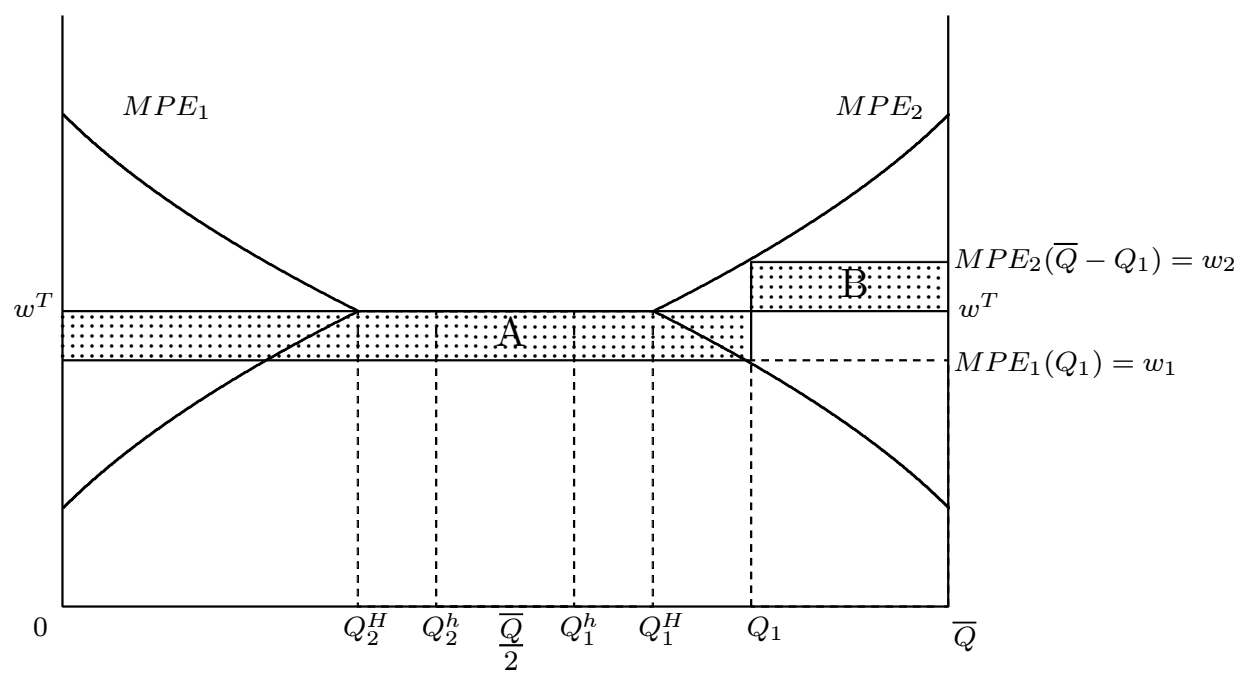

labor force that is employed in the private sector of $G C C$ countries is usually very small, in Kuwait 90 percent of the labor force in the private sector are migrant workers, so the allocation of licenses does not necessarily need to be very skewed in order for at least one firm to hire only migrant labor.

Firms will not use the same amount of effective labor in production if their marginal products of effective labor are not the same. What license allocation will lead to a difference in the marginal products of effective labor? With perfect substitutability of domestic and migrant labor the marginal product of effective labor for Firm $i$ is $F_{1}^{i}\left(E_{i}+E_{i}^{*}, K_{i}\right)$. Let $K_{i}=K$ for all firms so that firms are identical apart from their license allocations. Again, consider the two firm case. In Figure 3, the wage per effective unit of labor for each firm is graphed on the vertical axis and the quota allocation is graphed on the horizontal axis where $Q_{1}$ is the number of licenses allocated to Firm 1.

Assume both firms are allocated the same number of licenses, $\frac{\bar{Q}}{2}$. As the license allocation to Firm 1 increases, both firms can initially adjust the mix of domestic and foreign labor in order to use the same amount of effective labor units. When they hire the same number of effective units of labor, the outcome is the same as the transferable case. This will occur until Firm 1 hires only migrant labor. Let the smallest quota allocation such that Firm 1 uses only migrant labor be defined as $Q_{1}=Q_{1}^{h}$. Of course at this allocation, Firm 2 must be using all of the domestic labor in the economy as well as some migrant workers. For $\frac{\bar{Q}}{2} \leq Q_{1}<Q_{1}^{h}$, both firms hire the same average quality of workers, and use the same amount of effective labor. 
The average migrant worker type when $g($.$) is uniform is$

$$
\frac{[1+\underline{\theta}]}{2}=\left[1-\frac{\bar{Q}}{2 N^{*}}\right]
$$

so that $Q_{1}^{h}\left[1-\frac{\bar{Q}}{2 N^{*}}\right]$ equals the effective labor hired by Firm 1 . While Firm 1 hires only foreign labor (of the average quality), Firm 2 hires all the domestic labor as well as the remaining foreign labor, and both hire the same total effective labor. As total effective labor is $E+E^{*}$, each uses half of this. Thus

$$
Q_{1}^{h}\left[1-\frac{\bar{Q}}{2 N^{*}}\right]=\frac{E+E^{*}}{2} .
$$

Solving for $Q_{1}^{h}$ and using the fact that $\left[1-\frac{\bar{Q}}{2 N^{*}}\right] \bar{Q}=E^{*}$ gives

$$
Q_{1}^{h}=\bar{Q}\left[\frac{E+E^{*}}{2 E^{*}}\right] .
$$

As $Q_{1}$ increases beyond $Q_{1}^{h}$, firms can hire the same amount of effective labor by hiring different migrant labor types. This will be possible until Firm 1 is hiring the lowest productivity type workers and Firm 2 is hiring the highest productivity type workers. Denote the smallest quota allocation to Firm 1 such that Firm 1 uses only the lower productivity type migrant workers as $Q_{1}=Q_{1}^{H}$. For $Q_{1}^{h}<Q_{1} \leq Q_{1}^{H}$, Firm 1 uses only foreign labor. It has the same effective labor as the other firm but uses lower quality foreign labor. At $Q_{1}=Q_{1}^{H}$ Firm 1 hires the lowest labor types choosing to migrate and so cannot lower its average quality any further. Let $\eta\left(Q_{1}^{H}\right)$ be the highest quality of labor Firm 1 hires. Hence,

$$
\begin{aligned}
N^{*} \int_{\underline{\theta}(\bar{Q})}^{\eta\left(Q_{1}^{H}\right)} \theta g(\theta) d \theta & =E_{i}^{T} \\
& =\frac{E+E^{*}}{2}
\end{aligned}
$$

defines $\eta\left(Q_{1}^{H}\right)$ and in turn,

$$
N^{*} \int_{\underline{\theta}(\bar{Q})}^{\eta\left(Q_{1}^{H}\right)} g(\theta) d \theta=Q_{1}^{H}
$$

defines $Q_{1}^{H}$ where $\underline{\theta}(\bar{Q})$ is defined by (5). ${ }^{4}$

${ }^{4}$ When $g(\theta)$ is uniform, from (10) we get:

$$
N^{*}\left[\frac{\left[\eta\left(Q_{1}^{H}\right)^{2}\right]}{2}-\frac{\left[1-\frac{\bar{Q}}{N^{*}}\right]^{2}}{2}\right]=\left[\frac{E+E^{*}}{2}\right]
$$


Figure 4: Non-transferable Licenses in a Competitive Labor Market

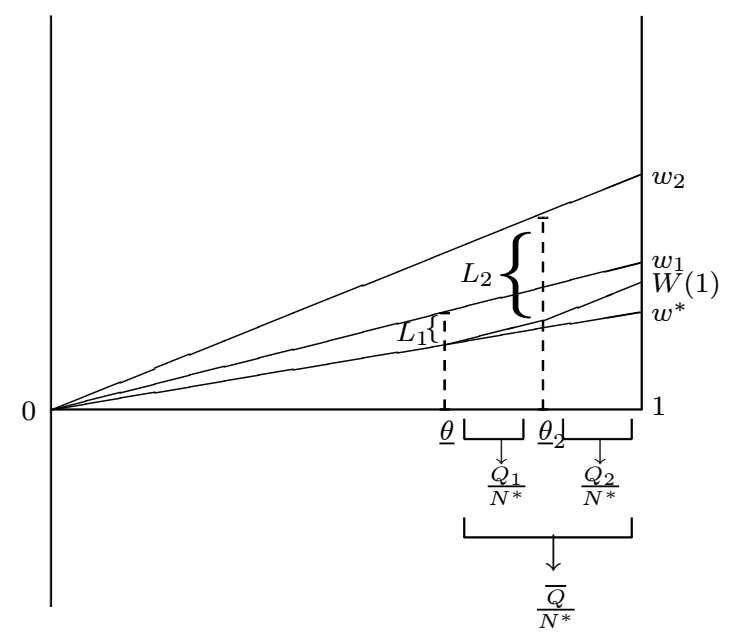

Finally, for $Q_{1}>Q_{1}^{H}$, Firm 1 hires more effective labor than Firm 2 and hence has a lower marginal product of effective labor, $w_{1}$.

In such cases we say that the allocation of licenses is severely distorted. Since Firm 2 employs both domestic and foreign workers, $w_{2}$ is also the domestic wage per effective unit of labor and $w_{2}>w_{1}$. The allocations $Q_{2}^{h}$ and $Q_{2}^{H}$ are symmetrically defined and depicted in Figure 3.

The wage schedules offered to migrant workers when firms have different marginal products of effective labor, that is, when $Q_{1}>Q_{1}^{H}$, are represented in Figure 4. In a competitive equilibrium each firm must still be indifferent between all of the labor types that it hires. Hence, (2) still holds for each firm though if they offer different wages, they attract different workers so that

$$
W_{i}(\theta)=w_{i} \theta-L_{i}
$$

Since $w_{2}>w_{1}, L_{2}$ must be more than $L_{1}$ for Firm 1 to attract any foreign workers. Since higher quality workers value a higher $w$ more than do lower quality ones, Firm 2 attracts the highest worker types and $L_{i}$ is determined to ensure that the number of migrant workers in each firm equals its license allocation. Let $\underline{\theta}_{2}$ denote the marginal worker hired by Firm 2 and recall that $\underline{\theta}$ denotes the marginal

which implicitly defines $\eta\left(Q_{1}^{H}\right)$, while $(11)$ gives

$$
Q_{1}^{H}=N^{*}\left[\eta\left(Q_{1}^{H}\right)-\underline{\theta}(\bar{Q})\right] .
$$


migrant worker in the domestic economy. The number of workers between $\underline{\theta}$ and $\underline{\theta}_{2}$ must equal $Q_{1}$ and $L_{1}$ must be such that it shifts the $\theta w_{1}$ line down to go through the point $\left(\underline{\theta}, w^{*} \underline{\theta}\right)$, while $L_{2}$ must be such that it shifts the $\theta w_{2}$ line down to go through the point $\left(\underline{\theta}_{2}, w_{1} \underline{\theta}_{2}-L_{1}\right)$. Note that the worker of type $\underline{\theta}_{2}$ is indifferent between working for either firm.

With $\theta$ distributed uniformly, $\underline{\theta}_{2}=1-\frac{Q_{2}}{N^{*}}$ and these conditions boil down to

$$
w_{2} \underline{\theta}_{2}-L_{2}=w_{1} \underline{\theta}_{2}-L_{1}
$$

and

$$
w_{1} \underline{\theta}-L_{1}=w^{*} \underline{\theta} .
$$

Thus:

$$
L_{1}=\left[w_{1}-w^{*}\right]\left[1-\frac{\bar{Q}}{N^{*}}\right]
$$

and

$$
L_{2}=\left[w_{2}-w_{1}\right]\left[1-\frac{Q_{2}}{N^{*}}\right]+\left[w_{1}-w^{*}\right]\left[1-\frac{\bar{Q}}{N^{*}}\right] .
$$

As the total effective labor from abroad is unchanged from the transferable case, if $w_{2}>w_{1}$ then Firm 1 hires more effective labor than it did under transferability while Firm 2 hires less. Hence $w_{2}>w>w_{1}$ so that domestic effective labor which earns $w_{2}$ is better off.

What are the effects of a skewed allocation of non-transferable licenses on the distribution of license rents? Since $w_{2}>w>w_{1}$ and both $w_{1} \theta-L_{1}$ and $w \theta-L$ emanate from the point $(\underline{\theta}, w \underline{\theta}-L)$ in Figure 4, it is clear that the wages of low quality migrant workers must be lower under non-transferability when the allocation of licenses is severely distorted. However, it is not clear that the migrant workers types hired by Firm 2 must earn less.

With transferable licenses, from (3) and (5), the wage schedule offered to migrant workers by all firms is

$$
W(\theta)=w^{T} \theta-\left[w^{T}-w^{*}\right]\left[1-\frac{\bar{Q}}{N^{*}}\right]
$$

where $w^{T}$ is the marginal product of effective labor when both firms use the same amount of effective labor. Using equations (12) and (16), Firm 2's wage schedule is

$$
W_{2}(\theta)=w_{2} \theta-\left[w_{2}-w_{1}\right]\left[1-\frac{Q_{2}}{N^{*}}\right]-\left[w_{1}-w^{*}\right]\left[1-\frac{\bar{Q}}{N^{*}}\right] .
$$


Comparing (17) and (18), each migrant worker type hired by Firm 2 will make less under non-transferability if

$$
\left[w^{T}-w_{1}\right] Q_{1}+N^{*}\left[w^{T}-w_{2}\right][1-\theta]>\left[w_{2}-w^{T}\right] Q_{2}
$$

If this condition holds for the highest type worker, $\theta=1$, then clearly it will also hold for all worker types hired by Firm 2. For $\theta=1$, Equation (19) simplifies to

$$
\left[w^{T}-w_{1}\right] Q_{1}>\left[w_{2}-w^{T}\right] Q_{2}
$$

In Figure 3, area $A$ is $\left[w^{T}-w_{1}\right] Q_{1}$ and area $B$ is $\left[w_{2}-w^{T}\right] Q_{2}$. So the condition holds as long as $A$ is greater than $B$.

When might this be true? Notice that at $Q_{1}=Q_{1}^{H}$, areas $A$ and $B$ disappear. As we just start to increase the quota allocation to Firm 1 from $Q_{1}=Q_{1}^{H}$, area $A$ is looks like it has to exceed than area $B$ since Firm 1 has a larger allocation of quota licenses. This suggests that for license allocations close to $Q_{1}=Q_{1}^{H}$, migrant workers hired by both firms will make less under non-transferability. Moreover, this remains true for all $Q_{1}>Q_{1}^{H}$ with a Cobb-Douglas production function. We show this formally below.

Theorem 1 When licenses are non-transferable and all firms do not have the same marginal product of effective labor the following will be true:

(1) All migrant workers hired by the firm with the largest allocation of licenses will receive lower wages than when licenses are transferable,

(2) With two firms and $g($.$) uniform, workers hired by the firm with the smaller$ allocation of licenses will also earn less for all $Q_{1} \in\left(Q_{1}^{H}, Q_{1}^{H}+A\right)$ for $A$ small enough.

(3) With two firms and $g($.$) uniform, workers hired by the firm with the smaller$ allocation of licenses earn less for all $Q_{1} \in\left(Q_{1}^{H}, \bar{Q}\right)$ if the production function for both firms takes a Cobb-Douglas form.

Proof. In the Appendix.

\subsection{Many Firms}

We now generalize these conditions to the $M$ firm case. Here there are two types of firms, type 1 and type 2, where we assume that, $Q_{1}$, the license allocation to each firm of type 1 is greater than, $Q_{2}$, the license allocation to each firm of type 
2. There are $\mu M$ symmetric firms of type 1 and $[1-\mu] M$ symmetric firms of type 2 , where $\mu$ denotes the proportion of firms that are of type 1 . Let $\bar{Q}$ equal the total number of licenses in the domestic economy, where

$$
\bar{Q}=M\left[\mu Q_{1}+[1-\mu] Q_{2}\right] .
$$

A change in $M$ implies that the number of firms has changed but that the proportion of firms of each type remains constant. This implies that an increase in $M$ leads to a proportional decrease in $Q_{1}$ and $Q_{2}$, as the total number of licenses in the economy is constant. A change in $\mu$ implies that the proportion of type 1 firms has changed but the number of firms remains constant. From (20), with $\bar{Q}$ fixed, $\mu Q_{1}+[1-\mu] Q_{2}$ must be constant. Keeping $Q_{1}$ fixed, this implies that an increase in $\mu$ must lead to a decrease in $Q_{2}$, as $Q_{1}$ is assumed to be greater than $Q_{2}$.

How do $M$ and $\mu$ affect $Q_{1}^{h}$ and $Q_{1}^{H}$ ? Again $Q_{1}^{h}$ is the minimum allocation to each firm of type 1 such that it uses only migrant labor. As before, equating the effective labor used by a firm of type 1, which is the number of licenses times the average migrant worker type, to each firms' share of the total effective labor in the economy, gives

$$
Q_{1}^{h}\left[1-\frac{\bar{Q}}{2 N^{*}}\right]=\frac{E+E^{*}}{M} .
$$

Using the fact that $\left[1-\frac{\bar{Q}}{2 N^{*}}\right] \bar{Q}=E^{*}$, gives

$$
Q_{1}^{h}=\bar{Q}\left[\frac{E+E^{*}}{M E^{*}}\right] .
$$

From (21), $Q_{1}^{h}$ is independent of $\mu$ and decreasing linearly in $M$. This is illustrated in Figure 5, with $\frac{1}{M}$ graphed on the horizontal axis and $Q_{1}$ graphed on the vertical axis. Intuitively, the point at which firms of type 1 can no longer trade off domestic for migrant labor only depends on the number of licenses each type 1 firm is allocated. As the number of firms increases, the allocation of licenses to each firm decreases. Thus, the point at which firms of type 1 are no longer able to trade off domestic for foreign labor occurs earlier and $Q_{1}^{h}$ falls as $M$ rises. However, increasing the proportion of type 1 firms, does not affect $Q_{1}^{h}$. This follows as we have assumed that the number of licenses allocated to each type 1 firm is constant when $\mu$ changes.

What about $Q_{1}^{H}$ ? At $Q_{1}^{H}$ firms of type 1 use the lowest quality migrant workers, but still have the same marginal product of migrant effective labor as firms of type 
2. Formally, $\eta\left(Q_{1}^{H}\right)$ is defined by setting the effective labor hired by all type 1 firms equal to each firms' share of total effective labor in the economy, $\frac{\left[E+E^{*}\right]}{M}$, times the number of type 1 firms, $\mu M$, where

$$
\begin{aligned}
N^{*} \int_{\underline{\theta}(\bar{Q})}^{\eta\left(Q_{1}^{H}\right)} \theta g(\theta) d \theta & =\frac{\left[E+E^{*}\right] \mu M}{M} \\
& =\left[E+E^{*}\right] Q_{1}^{H} \mu .
\end{aligned}
$$

$Q_{1}^{H}$ is defined by setting the number of workers hired by all type 1 firms, i.e. those between $\underline{\theta}$ and $\eta\left(Q_{1}^{H}\right)$, equal to the number of licenses held by all type 1 firms. Hence,

$$
N^{*} \int_{\underline{\theta}(\bar{Q})}^{\eta\left(Q_{1}^{H}\right)} g(\theta) d \theta=Q_{1}^{H} \mu M .
$$

From (22) we see that $\eta\left(Q_{1}^{H}\right)$ is independent of $M$ and increasing in $\mu$. This implies that the left hand side of (23) is fixed. As a result the product of $Q_{1}^{H}$ and $M$ must be constant when $M$ changes so that $Q_{1}^{H}$ must be decreasing linearly in $M$. This is illustrated in Figure 5, where $Q_{1}^{H}\left(\frac{1}{M}, \mu\right)$ is greater than $Q_{1}^{h}\left(\frac{1}{M}\right)$, when $M<\infty$. If $g($.$) is uniform, then (22) and (23) are given by$

$$
N^{*}\left[\frac{\eta\left(Q_{1}^{H}\right)^{2}-\underline{\theta}(\bar{Q})^{2}}{2}\right]=\left[E+E^{*}\right] \mu
$$

and

$$
N^{*}\left[\eta\left(Q_{1}^{H}\right)-\underline{\theta}(\bar{Q})\right]=Q_{1}^{H} \mu M
$$

respectively. Taking the ratio of (24) and (25) gives

$$
\eta\left(Q_{1}^{H}\right)+\underline{\theta}(\bar{Q})=\frac{2\left[E+E^{*}\right]}{Q_{1}^{H} M} .
$$

Since $\eta\left(Q_{1}^{H}\right)$ is increasing in $\mu, Q_{1}^{H}$ must be decreasing in $\mu$ for a given number of firms, $M$. This is drawn in Figure 5 where $\mu<\mu^{\prime}$. An increase in $\mu$ rotates the ray between 0 and $Q_{1}^{H}$ inward but does not affect $Q_{1}^{h}$. Thus, the interval $Q_{1}^{H}-Q_{1}^{h}$ decreases as $\mu$ increases. Since both $Q_{1}^{h}$ and $Q_{1}^{H}$ decrease proportionally as the number of firms increases, $Q_{1}^{H}-Q_{1}^{h}$ will decrease as $M$ increases. This implies that if a given allocation, $Q_{1}$, is initially below $Q_{1}^{H}$, it may end up above $Q_{1}^{H}$ as either $M$ or $\mu$ rise. 
Figure 5: Minimum Allocations for Firm 1 as a function of $\frac{1}{M}$ and $\mu$

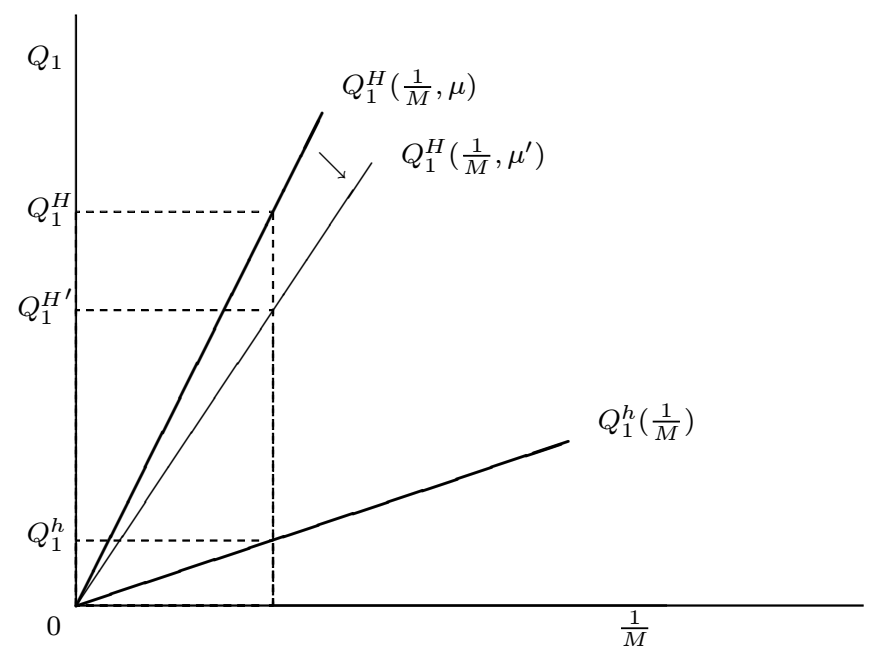

Theorem 2 With many firms using non-transferable licenses, and firms not having the same marginal product of effective labor, the following will be true:

(1) All migrant workers hired by the firm(s) with the largest allocation of licenses will receive lower wages than when licenses are transferable,

(2) With $g($.$) uniform, and assuming the total licenses allocated to firms of$ type 1 is greater than the total licenses allocated to firms of type 2, workers hired by type 2 firms will also earn less for all $Q_{1} \in\left(Q_{1}^{H}, Q_{1}^{H}+A\right)$ for $A$ small enough.

(3) With $g($.$) uniform, and assuming the total licenses allocated to firms of$ type 1 is greater than the total licenses allocated to firms of type 2, workers hired by type 2 firms earn less for all $Q_{1} \in\left(Q_{1}^{H}, \bar{Q}\right)$ if the production function for all firms takes a Cobb-Douglas form.

Proof. In the Appendix.

Intuitively, part (1) holds as $w_{1}<w^{T}<w_{2}$ when firms do not have the same marginal product of migrant effective labor and $Q_{1}>Q_{2}$. Part (2) can be understood by noting that at $Q_{1}^{H}$, all firms have the same wage. If the license allocation to all type 1 firms is very small, then the decrease in their marginal product of migrant effective labor from an increase in $Q_{1}$ implies only a small shift down in the aggregate wage schedule, $W(\theta)$. Thus, migrant workers of type $\theta=1$, will not earn less by being hired by firms of type 2 . Only when the total license allocation to type 1 firms is at least half of the total license allocation in the economy will all workers hired by firms of type 2 earn less. For part (3), the 
same condition applies. When the production function is Cobb-Douglas $w_{1}$ falls at a slower rate than $w_{2}$ rises, as $Q_{1}$ increases. A sufficient condition for workers of type $\theta=1$ to earn less working for firms of type 2 remains that the total license allocation to firms of type 1 be greater than the total license allocation to firms of type 2 .

\section{Imperfect Substitutes}

In this section we ask whether our results go through when domestic and foreign labor are imperfect substitutes. We show that the outcomes are similar. If a firm has more licenses than the other one, then for a while it will be able to hire the same effective foreign labor by hiring different qualities of migrant labor. After a point, namely when it is using the lowest quality migrant labor, it can no longer do so and it hires more effective foreign labor than the other firm and has a lower marginal product of foreign labor.

For simplicity, assume that all firms are ex ante identical and have a production function, $F\left(E, E^{*}, K\right)$. Take the optimal choice of $E$ for every given value of $E^{*}, w$ and $K$ and denote it by $E\left(E^{*}, w, K\right)$. This is implicitly defined by

$$
F_{E}\left(E, E^{*}, K\right)=w .
$$

Substitute $E\left(E^{*}, K\right)$ for $E$ in the production function. Let

$$
f\left(E^{*}, K, w\right)=F\left(E\left(E^{*}, K\right), E^{*}, K\right) .
$$

Now define the direct and indirect marginal product of a unit of $E^{*}$ as

$$
f_{E^{*}}\left(E^{*}, K, w\right)=F_{E}\left(E(.), E^{*}, K\right) E_{E^{*}}\left(E^{*}, w, K\right)+F_{E^{*}}\left(E(.), E^{*}, K\right) .
$$

If domestic and foreign labor are substitutes (complements), then an increase in $E^{*}$ shifts in (out) the marginal value product of $E$, resulting in a reduction (increase) in the optimal choice of $E$ so that $E\left(E^{*}\right)$ is downward (upward) sloping. When choosing $E^{*}$, the firm looks at its net marginal value product, $g_{E^{*}}\left(E^{*}, K, w\right)$, where

$$
g\left(E^{*}, K, w\right)=\left(f\left(E^{*}, K, w\right)-w E\left(E^{*}\right)\right) .
$$

Using the Envelope theorem the marginal product is just

$$
\begin{aligned}
g_{E^{*}}\left(E^{*}, K, w\right) & =F_{E}\left(E(.), E^{*}, K\right) E_{E^{*}}\left(E^{*}, w, K\right)+F_{E^{*}}\left(E(.), E^{*}, K\right)-w E_{E^{*}}\left(E^{*}, w, K\right) \\
& =F_{E^{*}}\left(E(.), E^{*}, K\right) .
\end{aligned}
$$


Figure 6: Supply and Demand of Migrant Effective Labor with Imperfect Labor Substitutes

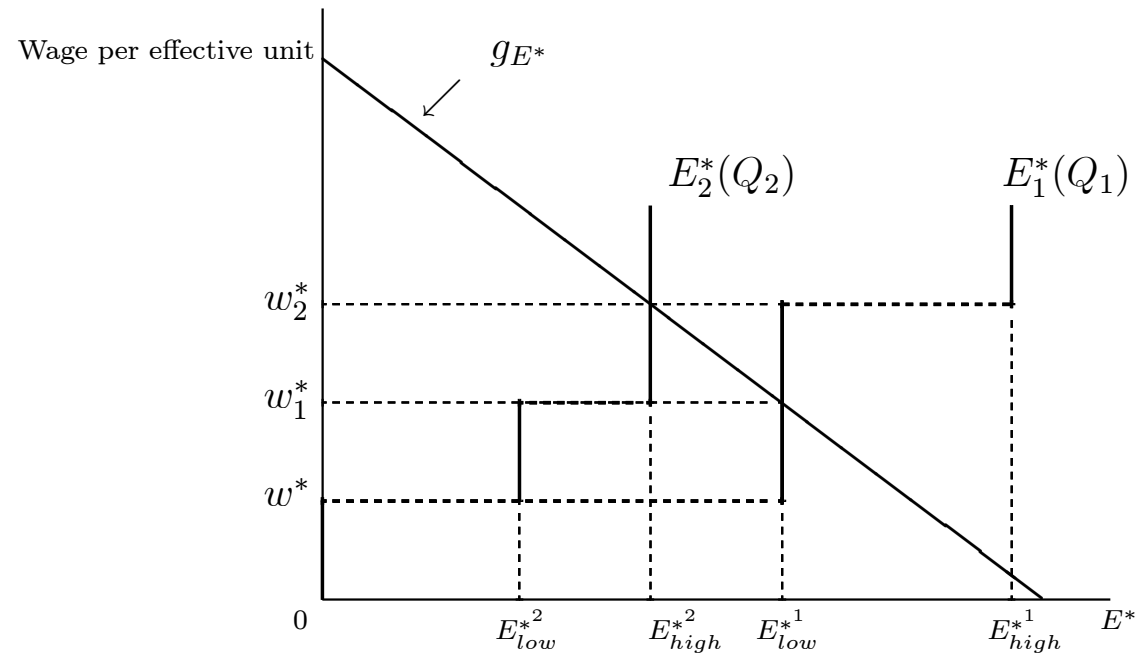

This is the demand for migrant effective labor as a function of migrant effective labor, capital, and the domestic wage per effective labor unit.

Assuming concavity of $F\left(E, E^{*}, K\right)$,

$$
g_{E^{*} E^{*}}(.)=F_{E^{*} E} E_{E^{*}}+F_{E^{*} E^{*}}<0 .
$$

Now that we have a direct and indirect willingness to pay for $E^{*}$, or a demand curve, we need to derive the supply side of the labor market. Let each firm be allocated $Q_{i}$ non-transferable licenses. To derive the supply schedule of migrant effective labor that firms face we need to look at the relationship between the equilibrium wage per effective unit of labor received by migrant workers and the effective labor units supplied to each firm.

We continue to use two firms to illustrate this. As discussed in previous sections, firms offer a wage schedule to migrant workers of

$$
W_{i}(\theta)=w_{i}^{*} \theta-L_{i}
$$

where $w_{i}^{*}$ is the equilibrium wage per effective unit of migrant labor for each firm and $L_{i}$ is the transfer payment offered to each firm by a migrant worker. If Firm 1 offers a wage per effective unit of labor less than that of the rest of the world, that is, $w_{1}^{*} \leq w^{*}$, they will not be able to hire any migrant workers from abroad. In this range, the supply schedule for effective labor is inelastic and equal to zero as seen in Figure 6.

If Firm 1 offers a wage per effective unit of labor greater than $w^{*}$ the productivity types and effective migrant labor supplied to them depends on the wage 
Figure 7-a: Wage Schedule for Firm 1 when $w^{*}<w_{1}^{*}<w_{2}^{*}$

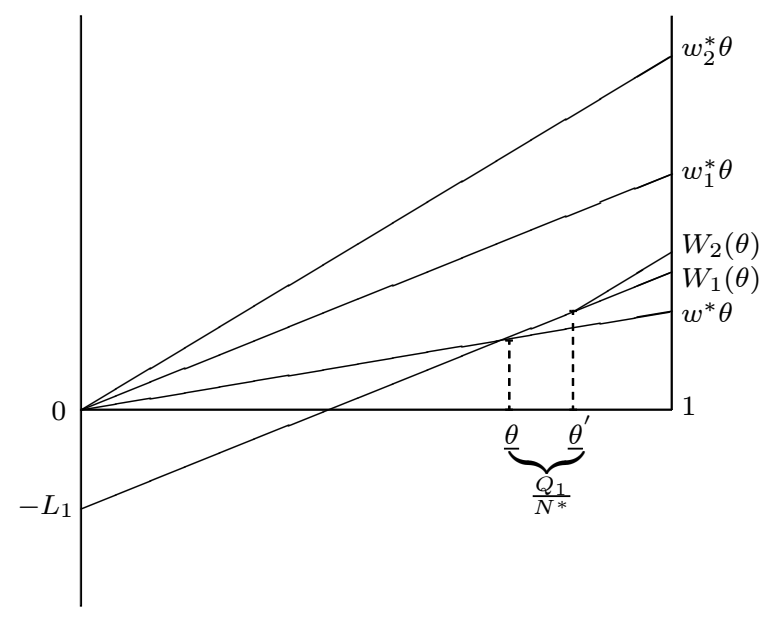

Figure 7-b: Wage Schedule for Firm 1 when $w_{1}^{*}>w_{2}^{*}$

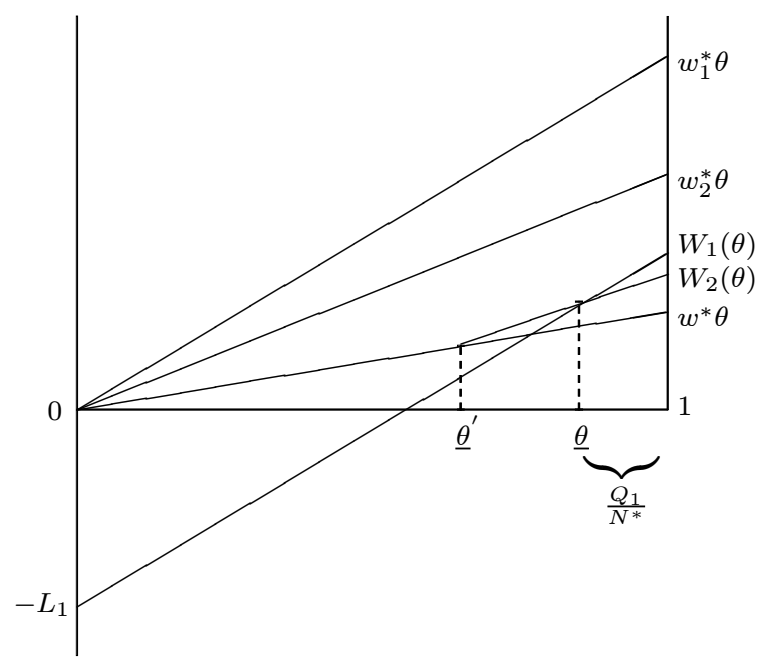


offered by Firm 2. If Firm 2 offers a higher wage, then only the lowest worker types migrating choose to work for Firm 1 since high worker types value the higher wage per effective unit of labor more than low worker types. This is depicted in Figure $7-a$. Thus for $w_{2}^{*}>w_{1}^{*}>w^{*}$, the supply of effective labor for Firm 1 is vertical at $E_{\text {low }}^{*^{1}}$ as depicted in Figure 6. If Firm 1 offers a wage equal to that of Firm 2 , it can certainly get a supply of $E_{\text {low }}^{*^{1}}$ if it hires only the lowest quality foreign workers. However, if it hires the highest quality, and this is no problem as workers are indifferent between working for the two firms, there is a discrete jump in the effective labor hired by Firm 1 and it can hire as many as $E_{\text {high }}^{*^{1}}$ units of foreign effective labor. Hence it faces a supply curve which is horizontal between $E_{\text {low }}^{*^{1}}$ and $E_{\text {high }}^{* 1}$. In Figure $7-b$, for any $w_{1}^{*}>w_{2}^{*}$, the highest worker types that migrate choose to work for Firm 1 and the supply of effective labor is vertical at $E_{\text {high }}^{*^{1}}$. The bids offered by migrant workers to both firms adjust such that the marginal worker hired by each firm is indifferent between working for that firm and their best alternative available.

We can go through a similar process to derive the supply schedule facing Firm 2. Note that an increase in the number of licenses shifts this supply curve to the right. The intersection of the supply schedule, which depends on the allocation of licenses, and the demand curve, which is common to all firms, gives the shadow price of a unit of $E^{*}$ or the wage per effective unit of migrant labor for each firm in equilibrium. Figure 6 depicts Firm 2 as having the smaller allocation of licenses and thus a higher shadow price of a unit of $E^{*}$ where the supply schedule for Firm 2 is to the left of the supply schedule for Firm 1.

We can define $Q_{1}^{H}$ and $Q_{2}^{H}\left(=\bar{Q}-Q_{1}^{H}\right)$ as before. $Q_{1}^{H}$ is the highest quota license allocation for Firm 1 consistent with equal equilibrium wages, $w^{T}$, for the two firms. This is depicted in Figure 8, where the quota allocation to Firm 1 is $Q_{1}^{H}$. As $Q_{1}$ increases, the supply schedule for Firm 1 shifts to the right and the supply schedule for Firm 2 shifts to the left. A higher license allocation for Firm 1 when $Q_{1}>Q_{1}^{H}$ must result in a lower equilibrium wage offered to migrant workers by Firm 1 and a higher wage offered by Firm 2 as illustrated in Figure 6. It is easy to see that the first two parts of Theorem 1 remain true even when domestic and foreign labor are differentiated. Part (3) is shown in the Appendix where migrant and foreign effective labor now enter separately in the production function. 
Figure 8: Supply and Demand of Migrant Effective Labor with $Q_{1}=Q_{1}^{H}$

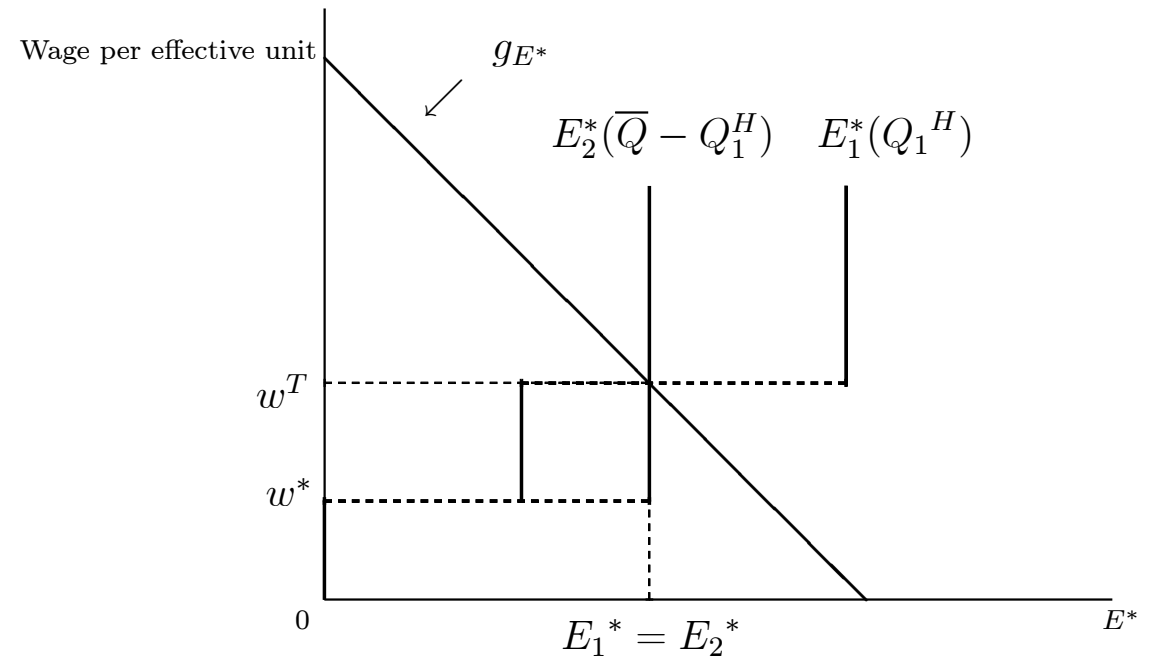

\section{Conclusion}

Throughout this paper we have looked at how implementation of migration policies can affect both the allocation of worker types amongst firms in the economy and the efficiency of the economy as a whole. In particular, when licenses are nontransferable and firms do not have the same marginal product of effective labor, firms offer different wage schedules to migrant workers in equilibrium, there are efficiency losses in the economy, and under certain conditions a greater share of migration rents accrue to firms. Similar results are obtained when domestic and foreign labor inputs are not perfect substitutes and allocations of licenses are unequal. This may be a reason why non-transferable migration licenses are used in $G C C$ countries where firms have a considerable amount of political power.

\section{Appendix}

Proof of Theorem 1 Part (1) follows as $w_{1}<w^{T}<w_{2}$ for all $Q_{1} \in\left(Q_{1}^{H}, \bar{Q}\right)$. For parts $(2)$ and $(3)$ we need to test whether or not $\left[w^{T}-w_{1}\right] Q_{1}-\left[w_{2}-\right.$ $\left.w^{T}\right]\left[\bar{Q}-Q_{1}\right]>0$. This condition becomes

$$
w^{T} \bar{Q}>w_{1} Q_{1}+w_{2} Q_{2} .
$$

Since the left hand side is constant, if we show that the right hand side of (27) is decreasing in $Q_{1}$ at $Q_{1}^{H}$, we will have shown part (2). Let $F_{1}^{i}$ be the 
marginal product of effective labor for Firm $i$. Taking the derivative of both sides, and evaluating it at $Q_{1}=Q_{1}^{H}$ gives us the condition:

$$
0>F_{1}^{1}+F_{11}^{1} \frac{d E_{1}^{*}}{d Q_{1}} Q_{1}-F_{1}^{2}+F_{11}^{2} \frac{d E_{2}^{*}}{d Q_{1}} Q_{2}
$$

Note that the following facts are true. First, $\frac{d E_{2}^{*}}{d Q_{1}}=-\frac{d E_{1}^{*}}{d Q_{1}}$. Second, that at $Q_{1}=Q_{1}^{H}, F_{1}^{1}=F_{1}^{2}$ and $F_{11}^{1}=F_{11}^{2}$. Third, that $Q_{1}-Q_{2}>0$. Fourth, that $F_{11}^{1}<0$ by concavity. Last, that $\frac{d E_{1}^{*}}{d Q_{1}}>0$ for all $Q_{1} \in\left(Q_{1}^{H}, Q_{1}^{H}+A\right)$ for $A$ small enough. Hence the right hand side of (28) equals

$$
F_{11}^{1}\left[Q_{1}-Q_{2}\right] \frac{d E_{1}^{*}}{d Q_{1}}<0
$$

Since this is a strict inequality, (28) holds in a small region close to $Q_{1}^{H}$ which proves the second part of Theorem 1.

If we show that the right hand side of (27) is decreasing in $Q_{1}$ at all $Q_{1} \geq Q_{1}^{H}$ for a Cobb-Douglas production function, we will have shown part (3).

Let

$$
F^{i}\left(E_{i}, K\right)=E_{i}^{\alpha} K^{(1-\alpha)} .
$$

For $Q_{1}>Q_{1}^{H},(28)$ becomes

$$
w_{2}-w_{1}>F_{11}^{1} \frac{d E_{1}^{*}}{d Q_{1}} Q_{1}-F_{11}^{2} \frac{d E_{2}^{*}}{d Q_{2}} Q_{2}
$$

as $\frac{d E_{2}^{*}}{d Q_{1}}=-\frac{d E_{1}^{*}}{d Q_{1}}=\frac{d E_{1}^{*}}{d Q_{2}}=-\frac{d E_{2}^{*}}{d Q_{2}}$ and $w_{1}=F_{1}^{1}, w_{2}=F_{1}^{2}$.

Note that

$$
\frac{d \log w_{i}}{d \log Q_{i}}=\frac{d w_{i}}{d Q_{i}} \frac{Q_{i}}{w_{i}}=F_{11}^{i} \frac{d E_{i}^{*}}{d Q_{i}} \frac{Q_{i}}{w_{i}} .
$$

Thus,

$$
\begin{aligned}
& w_{2}-w_{1}>\frac{d \log w_{1}}{d \log Q_{1}} w_{1}-\frac{d \log w_{2}}{d \log Q_{2}} w_{2} \text { or } \\
& w_{2}-w_{1}>\frac{d \log w_{1}}{d \log E_{1}^{*}} \frac{d \log E_{1}^{*}}{d \log Q_{1}} w_{1}-\frac{d \log w_{2}}{d \log E_{2}^{*}} \frac{d \log E_{2}^{*}}{d \log Q_{2}} w_{2} .
\end{aligned}
$$

Now

$$
\begin{aligned}
& E_{1}^{*}=Q_{1} q_{1} \\
& E_{2}^{*}=Q_{2} q_{2}
\end{aligned}
$$


where $q_{i}$ is the average migrant worker type hired by Firm $i$. Then

$$
\begin{aligned}
& \frac{d \log E_{1}^{*}}{d \log Q_{1}}=1+\frac{d \log q_{1}}{d \log Q_{1}} \\
& \frac{d \log E_{2}^{*}}{d \log Q_{2}}=1+\frac{d \log q_{2}}{d \log Q_{2}} .
\end{aligned}
$$

Define $\phi=-\frac{d \log q_{2}}{d \log Q_{2}}$ and $\psi=\frac{d \log q_{1}}{d \log Q_{1}}$. When $Q_{1}$ rises, worker quality rises for Firm 1 and falls for Firm 2. Hence, both $\phi$ and $\psi$ are non-negative. Using the above in (29) gives us

$$
w_{2}-w_{1}>\left[w_{1} \frac{d \log w_{1}}{d \log E_{1}^{*}}[1+\psi]-w_{2} \frac{d \log w_{2}}{d \log E_{2}^{*}}[1-\phi]\right] .
$$

In the Cobb-Douglas case,

$$
\frac{d \log w}{d \log E^{*}}=\alpha-1
$$

so that (30) becomes

$$
w_{2}-w_{1}>[\alpha-1]\left[w_{1}[1+\psi]-w_{2}[1-\phi]\right] .
$$

Rearranging terms gives (31) to be

$$
\left.\left[w_{2}-w_{1}\right] \alpha>[\alpha-1]\left[w_{1} \psi+w_{2} \phi\right]\right] .
$$

The left hand side is positive when $Q_{1}>Q_{1}^{H}$ since $\left[w_{2}-w_{1}\right]>0$ in this case. The right hand side is negative as $\alpha<1$. Hence, this inequality always holds! This completes the proof.

Proof of Theorem 2 Here let $Q_{1}$ and $Q_{2}$ be the number of licenses allocated to each firm of type 1 and type 2 respectively. If there are $\mu M$ firms of type 1 and $[1-\mu] M$ firms of type 2 the total license allocation to firms of type 1 and type 2 are $\mu M Q_{1}$ and $[1-\mu] M Q_{2}$. Let $\bar{Q}$ equal the total number of licenses in the domestic economy, where $\bar{Q}=M\left[\mu Q_{1}+[1-\mu] Q_{2}\right]$.

Part (1) holds by construction as $w_{1}<w^{T}<w_{2}$ for all $Q_{1} \in\left(Q_{1}^{H}, \bar{Q}\right)$. For parts (2) and (3), we again need to check whether all workers hired by firms of type 2 earn less with non-transferable licenses for the conditions stated above in Theorem 2. In the two firm case this condition is given by 
$W(\theta)>W_{2}(\theta)$, and if this holds for $\theta=1$ it will hold for all other migrant worker types. Expanded, this condition is

$$
w^{T}-\left[w^{T}-w^{*}\right] \underline{\theta}>w_{2}-\left[w_{2}-w_{1}\right] \eta\left(Q_{1}^{H}\right)-\left[w_{1}-w^{*}\right] \underline{\theta} .
$$

The lowest worker type, $\underline{\theta}$, is only a function of $\bar{Q}$. A change in the total number of firms will not affect the lowest worker type or $\eta\left(Q_{1}^{H}\right)$ as shown earlier.

Thus, our condition becomes

$$
w^{T}[1-\underline{\theta}]>w_{2}\left[1-\eta\left(Q_{1}^{H}\right)\right]+w_{1}\left[\eta\left(Q_{1}^{H}\right)-\underline{\theta}\right] .
$$

With a uniform distribution, the lowest migrant worker type is

$$
\underline{\theta}=1-\frac{\bar{Q}}{N^{*}} .
$$

The highest migrant worker type hired by type 1 firms equals the lowest migrant worker type in the economy, $\underline{\theta}$, plus the number of workers hired by firms of type 1 , where

$$
\begin{aligned}
\eta\left(Q_{1}^{H}\right) & =\underline{\theta}+\frac{\mu M Q_{1}}{N^{*}} \\
& =1-\frac{\bar{Q}}{N^{*}}+\frac{\mu M Q_{1}}{N^{*}} .
\end{aligned}
$$

Substituting (34) and (33) into (32) and multiplying both sides by $N^{*}$ gives

$$
w^{T} \bar{Q}>w_{2}\left[\bar{Q}-\mu M Q_{1}\right]+w_{1} \mu M Q_{1} .
$$

Equation (35) can also be written as

$$
\left[w^{T}-w_{1}\right] \mu M Q_{1}>\left[w_{2}-w^{T}\right]\left[\bar{Q}-\mu M Q_{1}\right] .
$$

Intuitively, when $Q_{1}>Q_{1}^{H}$, all migrant workers hired by firms of type 2 earn less under non-transferability if the total decrease in wages lost by firms of type $1,\left[w^{T}-w_{1}\right] \mu M Q_{1}$, is greater than the total gain in wages for firms of type $2,\left[w_{2}-w^{T}\right]\left[\bar{Q}-\mu M Q_{1}\right]$. Since $Q_{1}>Q_{2}$ by assumption, 
$\left[w_{2}-w^{T}\right]>\left[w^{T}-w_{1}\right]$ for all $Q_{1}>Q_{1}^{H}$, if $\left|\frac{d w_{2}}{d Q_{1}}\right|>\left|\frac{d w_{1}}{d Q_{1}}\right|$. When the production function is Cobb-Douglas, $F_{11}^{2}>F_{11}^{1}$, so

$$
\begin{aligned}
\left|\frac{d w_{2}}{d Q_{1}}\right| & =\left|F_{11}^{2} \frac{d E_{2}^{*}}{d Q_{1}}\right| \\
& >\left|F_{11}^{1} \frac{d E_{1}^{*}}{d Q_{1}}\right| \\
& =\left|\frac{d w_{1}}{d Q_{1}}\right|
\end{aligned}
$$

as $\frac{d E_{1}^{*}}{d Q_{1}}=-\frac{d E_{2}^{*}}{d Q_{1}}$. Thus, a sufficient condition such that (35) holds is that the number of licenses allocated to type 1 firms must be greater than half of the licenses in the economy, or

$$
\mu M Q_{1}>\frac{\bar{Q}}{2}
$$

More formally, since the left hand side of (35) is constant, if the right hand side of (35) is decreasing in $Q_{1}$ at $Q_{1}^{H}+A$, for a sufficiently small $A$ we will have shown part (2). Let $F_{1}^{i}$ be the marginal product of effective labor for Firm $i$. Taking the derivative of both sides, and evaluating it at $Q_{1}=Q_{1}^{H}$ gives us the condition:

$$
\begin{aligned}
0 & >\mu M F_{1}^{1}+F_{11}^{1} \frac{d E_{1}^{*}}{d Q_{1}} \mu M Q_{1}-\mu M F_{1}^{2}+F_{11}^{2} \frac{d E_{2}^{*}}{d Q_{1}}\left[\bar{Q}-\mu M Q_{1}\right] \\
& \left.=F_{11}^{1}\left[2 \mu M Q_{1}-\bar{Q}\right]\right] \frac{d E_{1}^{*}}{d Q_{1}}
\end{aligned}
$$

because, $\frac{d E_{2}^{*}}{d Q_{1}}=-\frac{d E_{1}^{*}}{d Q_{1}}$, and $F_{1}^{1}=F_{1}^{2}$ and $F_{11}^{1}=F_{11}^{2}$ at $Q_{1}=Q_{1}^{H}$. Since $F_{11}^{1}<0$ by concavity, and $\frac{d E_{1}^{*}}{d Q_{1}}>0$ for all $Q_{1} \in\left(Q_{1}^{H}, Q_{1}^{H}+A\right)$ for $A$ small enough, as expected, the right hand side of (36) is negative if $\mu M Q_{1}>\frac{\bar{Q}}{2}$ which is assumed to be true. This proves the second part of Theorem 2 .

If we show that the right hand side of (35) is decreasing in $Q_{1}$ at all $Q_{1} \geq Q_{1}^{H}$ for all $M$ when firms use a Cobb-Douglas production function, we will have shown (3).

Let

$$
F^{i}\left(E_{i}, K\right)=E_{i}^{\alpha} K^{(1-\alpha)} .
$$


For $Q_{1}>Q_{1}^{H}$, becomes

$$
\mu M\left[w_{2}-w_{1}\right]>F_{11}^{1} \frac{d E_{1}^{*}}{d Q_{1}} \mu M Q_{1}-F_{11}^{2} \frac{d E_{2}^{*}}{d Q_{2}}\left[\bar{Q}-\mu M Q_{1}\right]
$$

as $\frac{d E_{2}^{*}}{d Q_{1}}=-\frac{d E_{1}^{*}}{d Q_{1}}=\frac{d E_{1}^{*}}{d Q_{2}}=-\frac{d E_{2}^{*}}{d Q_{2}}$ and $w_{1}=F_{1}^{1}, w_{2}=F_{1}^{2}$.

Note that

$$
\frac{d \log w_{i}}{d \log Q_{i}}=\frac{d w_{i}}{d Q_{i}} \frac{Q_{i}}{w_{i}}=F_{11}^{i} \frac{d E_{i}^{*}}{d Q_{i}} \frac{Q_{i}}{w_{i}} .
$$

Thus,

$$
\mu M\left[w_{2}-w_{1}\right]>\frac{d \log w_{1}}{d \log Q_{1}} w_{1} \mu M-\frac{d \log w_{2}}{d \log Q_{2}} w_{2} \frac{\left[\bar{Q}-\mu M Q_{1}\right]}{Q_{2}} .
$$

As

$$
Q_{2}=\frac{\left[\bar{Q}-\mu M Q_{1}\right]}{[1-\mu] M}
$$

dividing both sides of (37) by $\mu M$, gives

$$
w_{2}-w_{1}>\frac{d \log w_{1}}{d \log Q_{1}} w_{1}-\frac{d \log w_{2}}{d \log Q_{2}} w_{2} \frac{[1-\mu]}{\mu} .
$$

Notice that (38) is not a function of the number of firms, $M$. Now

$$
\begin{aligned}
& E_{1}^{*}=Q_{1} q_{1} \\
& E_{2}^{*}=Q_{2} q_{2}
\end{aligned}
$$

where $q_{i}$ is the average migrant worker type hired by a firm of type $i$. So

$$
\begin{aligned}
& \frac{d \log E_{1}^{*}}{d \log Q_{1}}=1+\frac{d \log q_{1}}{d \log Q_{1}} \\
& \frac{d \log E_{2}^{*}}{d \log Q_{2}}=1+\frac{d \log q_{2}}{d \log Q_{2}} .
\end{aligned}
$$

Define $\phi=-\frac{d \log q_{2}}{d \log Q_{2}}$ and $\psi=\frac{d \log q_{1}}{d \log Q_{1}}$. When $Q_{1}$ rises, worker quality rises for Firm 1 and falls for Firm 2. Hence, both $\phi$ and $\psi$ are non-negative. Using the above in (38) gives us

$$
w_{2}-w_{1}>\left[w_{1} \frac{d \log w_{1}}{d \log E_{1}^{*}}[1+\psi]-w_{2} \frac{d \log w_{2}}{d \log E_{2}^{*}}[1-\phi] \frac{[1-\mu]}{\mu}\right] .
$$


In the Cobb-Douglas case,

$$
\frac{d \log w}{d \log E^{*}}=\alpha-1
$$

so that (39) becomes

$$
w_{2}-w_{1}>[\alpha-1]\left[w_{1}[1+\psi]-w_{2}[1-\phi] \frac{[1-\mu]}{\mu}\right] .
$$

Rearranging terms gives (40) to be

$$
\left.w_{2}\left[1-[\alpha-1] \frac{[1-\mu]}{\mu}\right]-w_{1} \alpha>[\alpha-1]\left[w_{1} \psi+w_{2} \phi \frac{[1-\mu]}{\mu}\right]\right] .
$$

The right hand side is negative as $\alpha<1$. Since $w_{2}>w_{1}$, the right hand side will always be positive when

$$
1-[\alpha-1] \frac{[1-\mu]}{\mu}>\alpha .
$$

Rearranging, this becomes

$$
\begin{aligned}
\frac{[1-\mu]}{\mu} & <\frac{1}{2} \text { or } \\
\mu & >\frac{1}{2} .
\end{aligned}
$$

Again if $\mu M Q_{1}>\frac{\bar{Q}}{2}, \mu$ is minimized at $\bar{Q}=M Q_{1}$. This implies that $\mu>\frac{1}{2}$. As such, the right hand side of (41) is always positive. Hence, this inequality holds when the total license allocation to firms of type 1 is greater than half of the migration licenses in the economy. This completes the proof.

Imperfect Labor Substitutes With imperfect labor substitutes the Cobb-Douglas production function used by all firms is

$$
F^{i}\left(E_{i}^{*}, E_{i}, K\right)=E_{i}^{*^{\alpha}} E_{i}^{\beta} K^{(1-\alpha-\beta)} .
$$

The marginal product of migrant effective labor is just

$$
\begin{aligned}
g_{E^{*}}^{i}\left(E^{*}, K, w\right) & =F_{E^{*}}^{i}\left(E^{*}, E(.), K\right) \\
& =\alpha \frac{F^{i}\left(E_{i}^{*}, E_{i}, K\right)}{E_{i}^{*}} .
\end{aligned}
$$


Also,

$$
g_{E^{*} E^{*}}^{i}(.)=F_{E^{*} E}^{i} E_{E^{*}}^{i}+F_{E^{*} E^{*}}^{i}
$$

For $Q_{1}>Q_{1}^{H}$ and imperfect labor substitutes, (28) becomes

$$
w_{2}^{*}-w_{1}^{*}>g_{E^{*} E^{*}}^{1} \frac{d E_{1}^{*}}{d Q_{1}} Q_{1}-g_{E^{*} E^{*}}^{2} \frac{d E_{2}^{*}}{d Q_{2}} Q_{2}
$$

as $\frac{d E_{2}^{*}}{d Q_{1}}=-\frac{d E_{2}^{*}}{d Q_{2}}=-\frac{d E_{1}^{*}}{d Q_{1}}=\frac{d E_{1}^{*}}{d Q_{2}}$ and $g_{E^{*}}^{i}=w_{i}^{*}$.

Note that

$$
\begin{aligned}
\frac{d \log w_{i}^{*}}{d \log Q_{i}} & =\frac{d w_{i}^{*}}{d Q_{i}} \frac{Q_{i}}{w_{i}^{*}} \\
& =\left[\frac{d w_{i}^{*}}{d E_{i}^{*}}+\frac{d w_{i}^{*}}{d E_{i}} \frac{d E_{i}}{d E_{i}^{*}}\right] \frac{d E_{i}^{*}}{d Q_{i}} \frac{Q_{i}}{w_{i}^{*}} \\
& =g_{E^{*} E^{*}}^{i} \frac{d E_{i}^{*}}{d Q_{i}} \frac{Q_{i}}{w_{i}^{*}}
\end{aligned}
$$

Thus,

$$
\begin{aligned}
& w_{2}^{*}-w_{1}^{*}>\frac{d \log w_{1}^{*}}{d \log Q_{1}} w_{1}^{*}-\frac{d \log w_{2}^{*}}{d \log Q_{2}} w_{2}^{*} \text { or } \\
& w_{2}^{*}-w_{1}^{*}>\frac{d \log w_{1}^{*}}{d \log E_{1}^{*}} \frac{d \log E_{1}^{*}}{d \log Q_{1}} w_{1}^{*}-\frac{d \log w_{2}^{*}}{d \log E_{2}^{*}} \frac{d \log E_{2}^{*}}{d \log Q_{2}} w_{2}^{*}
\end{aligned}
$$

Now

$$
\begin{aligned}
& E_{1}^{*}=Q_{1} q_{1} \\
& E_{2}^{*}=Q_{2} q_{2}
\end{aligned}
$$

where $q_{i}$ is the average migrant worker type hired by Firm $i$. Then

$$
\begin{aligned}
& \frac{d \log E_{1}^{*}}{d \log Q_{1}}=1+\frac{d \log q_{1}}{d \log Q_{1}} \\
& \frac{d \log E_{2}^{*}}{d \log Q_{2}}=1+\frac{d \log q_{2}}{d \log Q_{2}} .
\end{aligned}
$$

Define $\phi=-\frac{d \log q_{2}}{d \log Q_{2}}$ and $\psi=\frac{d \log q_{1}}{d \log Q_{1}}$. When $Q_{1}$ rises, worker quality rises for Firm 1 and falls for Firm 2. Hence, both $\phi$ and $\psi$ are non-negative. Using the above in (43) gives us

$$
w_{2}^{*}-w_{1}^{*}>\left[w_{1}^{*} \frac{d \log w_{1}^{*}}{d \log E_{1}^{*}}[1+\psi]-w_{2}^{*} \frac{d \log w_{2}^{*}}{d \log E_{2}^{*}}[1-\phi]\right] .
$$


In the Cobb-Douglas case, using (26),

$$
E=\left[\frac{w}{\beta E^{*^{\alpha}} K^{1-\alpha-\beta}}\right]^{\frac{1}{\beta-1}} .
$$

Substituting this back into the production function,

$$
g\left(E^{*}, K, w\right)=E^{*^{\frac{\alpha}{1-\beta}}}\left[\frac{w}{\beta}\right]^{\frac{\beta}{\beta-1}} K^{\frac{[1-\alpha-\beta]}{1-\beta}} .
$$

From (42),

$$
\begin{aligned}
\log w^{*} & =\log \left[\alpha \frac{g\left(E^{*}, K, w\right)}{E^{*}}\right] \\
& =\log \alpha+\log g\left(E^{*}, K, w\right)-\log E_{i}^{*}
\end{aligned}
$$

and

$$
\frac{d \log w^{*}}{d \log E^{*}}=\frac{\alpha}{1-\beta}-1
$$

Thus, (44) becomes

$$
w_{2}^{*}-w_{1}^{*}>\left[\frac{\alpha}{1-\beta}-1\right]\left[w_{1}^{*}[1+\psi]-w_{2}^{*}[1-\phi]\right] .
$$

Rearranging terms gives (45) to be

$$
\left.\left[w_{2}^{*}-w_{1}^{*}\right] \frac{\alpha}{1-\beta}>\left[\frac{\alpha}{1-\beta}-1\right]\left[w_{1} \psi+w_{2} \phi\right]\right] .
$$

The left hand side is positive when $Q_{1}>Q_{1}^{H}$ since $\left[w_{2}^{*}-w_{1}^{*}\right]>0$ and $\frac{\alpha}{1-\beta}>0$. The right hand side is negative as $\left[\frac{\alpha}{1-\beta}-1\right]<0$, since $1-\alpha-\beta>0$. Hence, this inequality always holds! This completes the proof. 


\section{References}

[1] Bhagwati, Jagdish. (1976) "The Brain Drain", International Social Science Journal, 28(4), pages 691-729.

[2] Djajic, Slobodan. (1989) "Skills and the Pattern of Migration: The Role of Qualitative and Quantitative Restrictions on International Labor Mobility", International Economic Review, 30(4), November, pp. 795-809.

[3] Hamada, Koichi. (1996) "Strategic Approaches to the International Economy: Selected Essays of Koichi Hamada". Elgar, Cheltenham, U.K. Previously published in 1975.

[4] Krishna, Kala and L. H. Tan. (1999) "Transferability versus NonTransferability: What is the Difference?" International Economic Review, August, Vol. 40 No. 3 pp. 785-800. 